\title{
HEPATITIS ANNUAL REPORT
}

A nalysis of trends of reported cases of hepatitis $\mathrm{A}$ and hepatitis B between 1982 and 1990 reflects evolving reporting mechanisms over this period, with the advent of Public Health Units (PHUs) and the transference of data collection from a centralised system (Health Department Epidemiology Branch) to a decentralised system (PHUs). Viral hepatitis is notifiable by all medical officers as hepatitis A, hepatitis B and hepatitis - unspecified. The introduction of the revised list of notifiable diseases requires the reporting of cases of acute viral hepatitis by all doctors, and laboratories will report cases of hepatitis A, hepatitis B, hepatitis C, hepatitis D (Delta hepatitis) and hepatitis E.

\section{HepatiTIS A}

The number of reported cases of hepatitis A for the period 1982 to 1990 ranged from 280 cases $(4.9 / 100,000)$ in 1986 to 32 cases $(0.6 / 100,000)$ in 1990 .

During 1990, six cases were reported for November and five for December, with fewer cases reported for the remaining months. Hepatitis A notifications were received from 10 areas and Regions, with the rate of notification ranging from $0.2 / 100,000$ and in the Hunter Area to 2.2/100,000 in the Wentworth Area.

The rate of hepatitis A notifications by sex was $0.6 / 100,000$ female and 0.7/100,000 male. Most cases were in the 15-19 and 30-39 age groups for males and the 40-49 age group for females.

\section{HEPATITIS B}

The number of reported cases of hepatitis B for the period 1982 to 1990 ranged from $174(3.1 / 100,000)$ in 1982 to 548 $(9.6 / 100,000)$ in 1985.

For $1990,444(7.8 / 100,000)$ cases of hepatitis B were reported. By month of onset, the number of reports ranged from 28 cases in December to 49 in May.

All Areas and Regions reported cases of hepatitis B, ranging from 46.0/100,000 for the Orana and Far Western Region to 1.5/100,000 for the Hunter Area. There was no seasonal variation in the reporting of hepatitis $B$ during 1990.

Hepatitis B was reported for all age groups, with a peak in the 20-39 age group for both males and females. Cases reported by sex were $186(6.5 / 100,000)$ for females and 162 $(5.7 / 100,000)$ for males. For the $20-39$ age group 58 per cent of cases were female and 42 per cent male.

\section{HepatiTIS C}

The total number of cases of hepatitis C for 1990 was 45 $(0.8 / 100,000)$. The number of cases reported by month of onset ranged from one in June and September to 10 in October.

Of the 45 cases of hepatitis $\mathrm{C}$ reported, 11 were female, 32 male and two unknown. For the 20-39 age group there were 24 males $(2.5 / 100,000)$ and seven females $(0.8 / 100,000)$.

\section{HEPATITIS D}

No cases of hepatitis D were reported during 1990.

\section{Hepatitis E}

No cases of hepatitis E were reported during 1990.

\section{FIGURE 7}

HEPATITIS A NOTIFICATIONS NSW 1982-1990

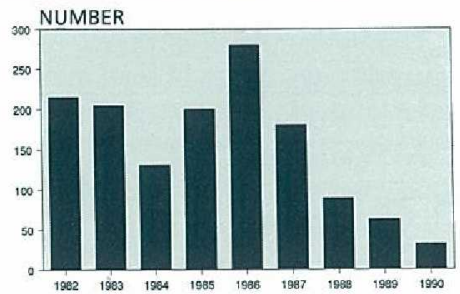

Source: NSW Infectious Disease Database.

\section{FIGURE 8}

HEPATITIS A - NSW 1990

NOTIFICATIONS BY AGE AND SEX

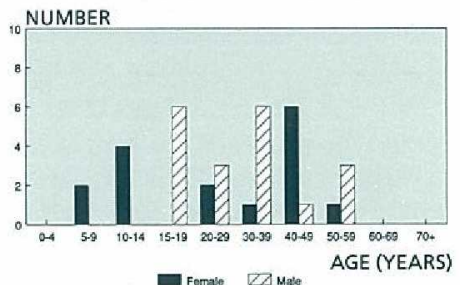

Source: NSW Infectious Disease Database

\section{FIGURE 9}

HEPATITIS B NOTIFICATIONS

NSW 1982-1990

NUMBER

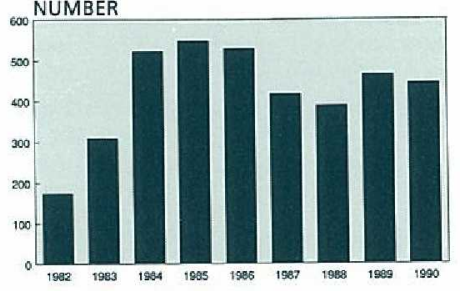

Source: NSW Infectious Disease Database.

\section{FIGURE 10}

HEPATITIS B - NSW 1990

NOTIFICATIONS BY AGE AND SEX

NUMBER

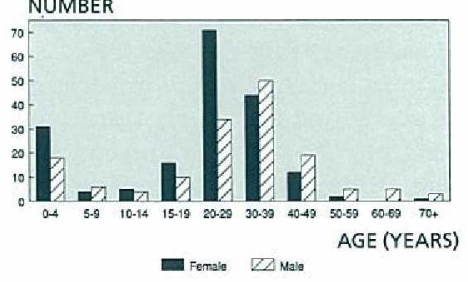

Source: NSW Infectious Disease Database

\section{FIGURE 11}

\section{HEPATITIS C - NSW 1990}

NOTIFICATIONS BY AGE AND SEX

NUMBER

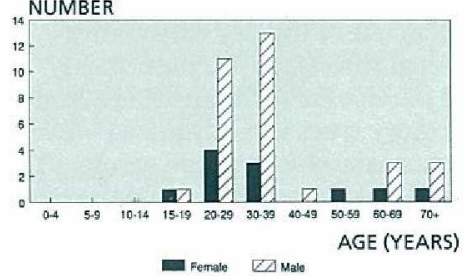

